\title{
Siyakha Nentsha: Building economic, health, and social capabilities among highly vulnerable adolescents in KwaZulu- Natal, South Africa
}

\author{
Kelly Hallman \\ Population Council \\ Eva Roca \\ Population Council
}

Follow this and additional works at: https://knowledgecommons.popcouncil.org/departments_sbsr-pgy

Part of the Demography, Population, and Ecology Commons, Family, Life Course, and Society Commons, Gender and Sexuality Commons, and the International Public Health Commons How does access to this work benefit you? Let us know!

\section{Recommended Citation}

Hallman, Kelly and Eva Roca. 2011. "Siyakha Nentsha: Building economic, health, and social capabilities among highly vulnerable adolescents in KwaZulu-Natal, South Africa," Promoting Healthy, Safe, and Productive Transitions to Adulthood Brief no. 4. New York: Population Council. 


\section{Siyakha Nentsha: Building economic, health, and social capabilities among highly vulnerable adolescents in KwaZulu-Natal, South Africa}

\section{Prepared by Kelly Hallman and Eva Roca}

Y oung people growing up in South Africa face many challenges. HIV, orphanhood, early pregnancy, and limited employment prospects are some of the major obstacles to a healthy and productive adulthood. In KwaZulu-Natal (KZN), the province with the highest HIV prevalence rates and one of only two where these rates are not declining (Shisana et al. 2009), the impact of HIV and AIDS is felt especially strongly. New infections and the stresses of coping with illness and loss of parents and caregivers are burdens that fall heavily on young people. In KZN, already-disadvantaged adolescents face the prospect of falling even further behind socially and economically because of the disruption of key relationships in their lives.

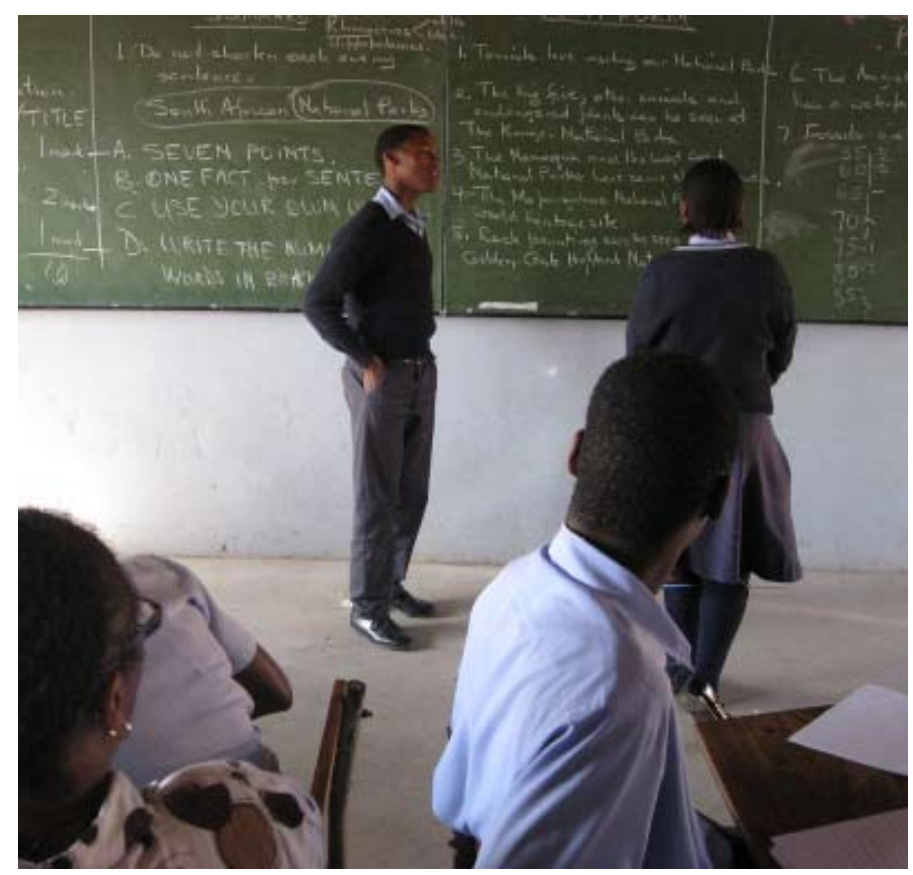

Based on years of formative research in $\mathrm{KZN}$, the Isihlangu Health and Development Agency and the Population Council developed and piloted a lifeorientation program, Siyakha Nentsha (isiZulu for "building with young people"), to improve the lifelong skills and well-being of young people. Focus group discussions with guardians and traditional leaders led to inclusion of both girls and boys in the program. Girls were a primary target population because of their vulnerability to HIV and early

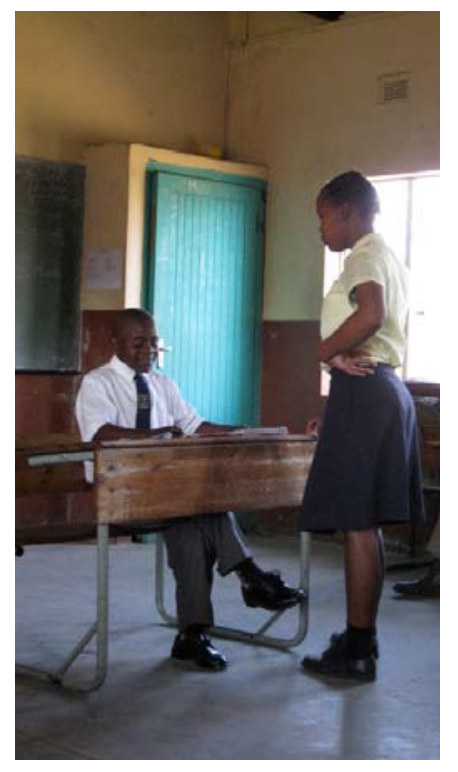
pregnancy; boys were included with the goal of building their knowledge and skills, and to allow girls and boys to work together, interact socially, learn to respect one another, and thus move beyond objectification of the opposite sex. This gave the program a unique opportunity to measure outcomes for both females and males in a setting where gender relations are often strained.

Siyakha Nentsha is a comprehensive and interactive program for girls and boys

Over 1,400 young people have participated in Siyakha Nentsha since 2008. The program took place in peri-urban communities of KwaZuluNatal Province, located outside of Durban and adjacent to the large township of Umlazi. Because the vast majority of young people in South Africa attend school during their teenage years, working through 
schools was the most effective way for the program to reach large numbers of participants and to avoid the sample selection bias of including only young people who had the means, transportation, and time to participate in an after-school or weekend program. The program aimed to work with young people who would be able to use the skills relatively quickly upon finishing school, yet not be too distracted by the program that they would lose time in grade 12 studying for their matric (secondary graduation certificate) exams. Siyakha Nentsha therefore included students who were in grades 10 and 11 at the beginning of the program. Each session was highly interactive and included time for participation and reflection.

Using local facilitators to deliver the program enhanced its effectiveness

Siyakha Nentsha was delivered by teams of intensively and continuously trained facilitators who were recent graduates from the schools and resided in the program communities. These young people participating in the program led one-hour sessions with students two to three times per week in classrooms during school hours. Facilitators were also available afterward to discuss personal issues faced by participants. Facilitators' familiarity with the community and the challenges faced by students made them more approachable to the study participants. The facilitators were carefully trained about confidentiality and procedures for service referrals in the event of duress or crisis faced by study participants.

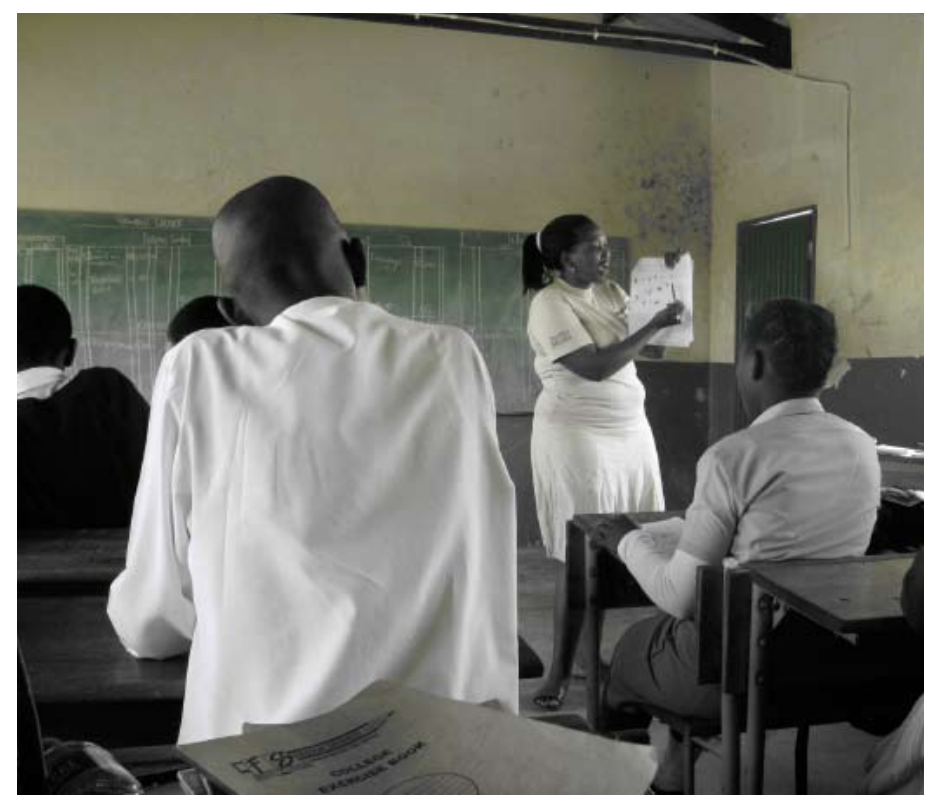

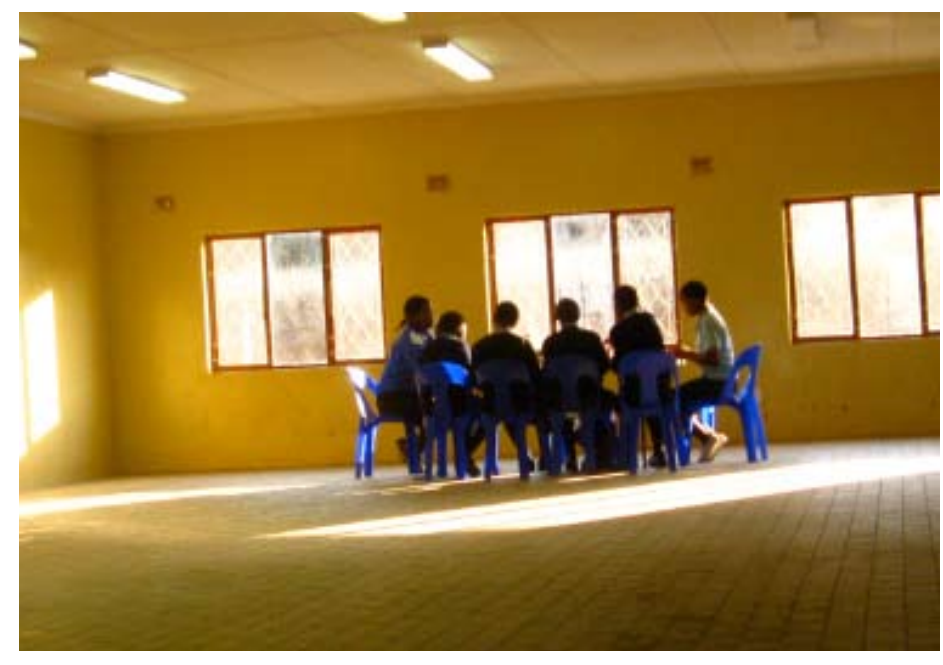

Testing a basic and an enhanced version of the program Siyakha Nentsha was designed to address the circumstances of highly vulnerable young people. Two versions were tested-a basic version that focused on developing social and health capabilities and an enhanced version that also included financial capabilities. These versions were compared against a control group that received standard lifeskills as delivered across South Africa. Siyakha Nentsha sessions included modules on self-awareness, human rights, HIV and AIDS, reproductive health, nutrition, planning for the future, saving money, accessing financial institutions, job readiness, and basic principles of starting a business. Within the six schools that participated in the program, the version tested was randomized by classroom.

Quantitative and qualitative measures provide a multi-faced picture of young people's lives

Program evaluation included quantitative and qualitative measures. Each participant was interviewed at his or her household before the program began and 18 months thereafter. In addition, focus group discussions were held with a sub-sample of participants, their caregivers, and the young adult facilitators who conducted the program. Results presented here are from the panel survey and are limited to data from participants who were interviewed in both rounds of the survey and who attended at least ten program sessions. The study had an attrition rate of only 11 percent-low for a study of adolescents, a population that is generally very mobile because of school leaving, job seeking, and family formation.

The baseline survey revealed that students' lives involve a host of challenges. Over one-third of young people in the study had lost at least one parent. Many participants lived with grandmothers, siblings, 


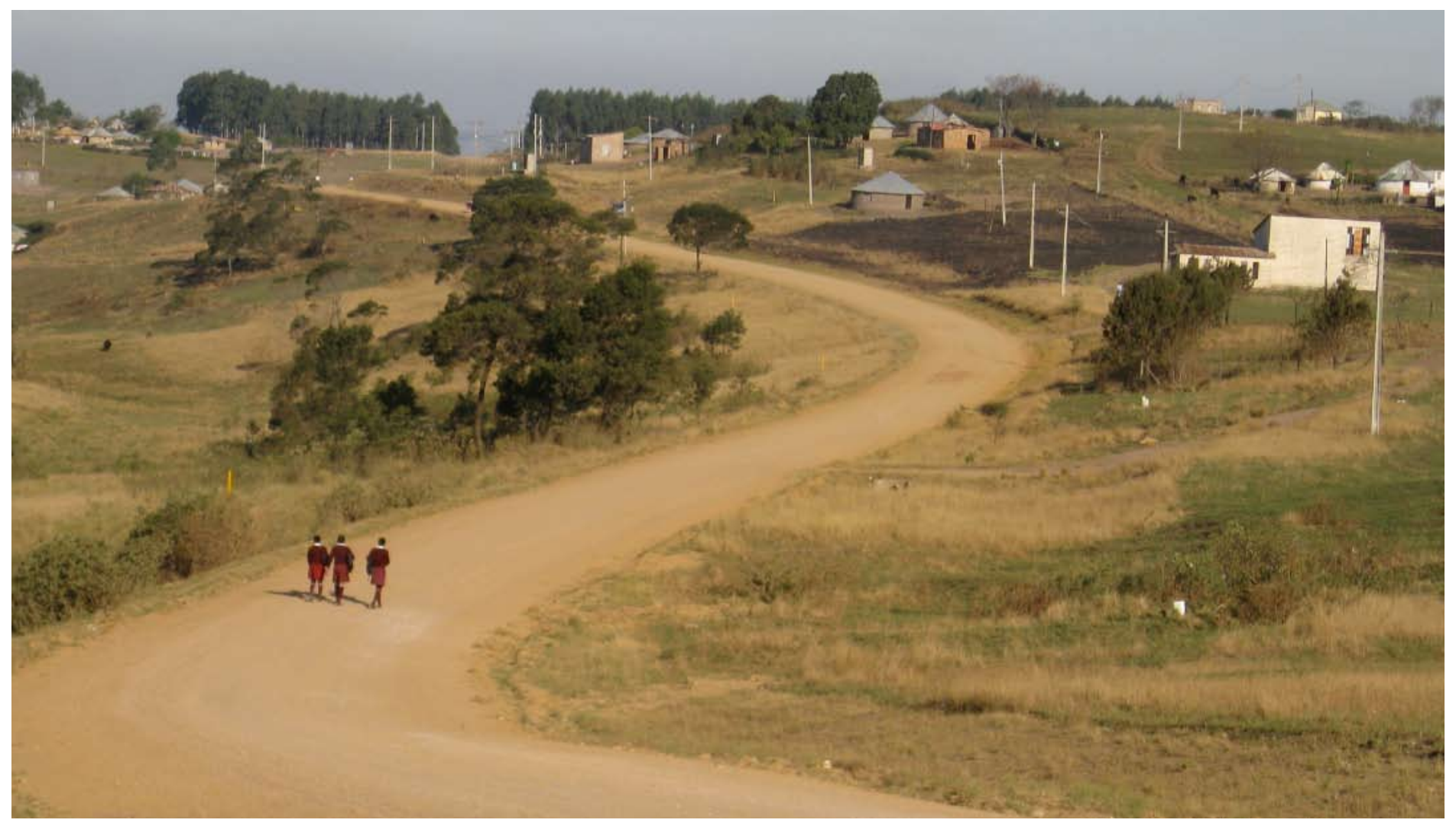

aunts, or uncles. Nearly one-fourth reported that their household did not have enough money for food and other basics. Most lived in homes connected to electricity but many reported frequent power outages. Eighty-eight percent of households were receiving some kind of social grant. Although schools were often located far from home, transport was lacking and most students walked to school. Almost one-fifth of girls, however, reported taking a taxi to school most days, possibly to avoid unsafe situations that can arise when girls walk alone. Reflecting the lack of employment opportunities in the area, only 17 percent of boys and 8 percent of girls at baseline had ever undertaken work for which they were paid.

\section{Siyakha Nentsha is making a difference for boys and girls}

Both the streamlined and full versions of Siyakha Nentsha led to important changes in young people's attitudes and behaviors, though the impacts differed between versions and between males and females. Compared to the control group, all Siyakha Nentsha participants (regardless of sex or version of the program) were more likely than those in the control group to know of a place to get condoms, reported a large increase in knowledge of social grant requirements and criteria, had improved budgeting and planning skills, and were more likely to have attempted to open a bank account.

Siyakha Nentsha girls (compared with girls in the control group) reported feeling higher self-esteem and greater confidence in their ability to obtain a condom if necessary. Siyakha Nentsha boys were more likely to have remained sexually abstinent between survey rounds, and Siyakha Nentsha boys who did have sex reported having fewer sexual partners than did boys in the control group. Among those of eligible age, boys participating in Siyakha Nentsha were more likely to have a South African ID than boys in the control group.

Compared with participants who received the partial Siyakha Nentsha package (health and social capabilities), girls with the full Siyakha Nentsha package (financial capabilities added) felt greater levels of social inclusion in their communities and were more likely to have obtained a national birth certificate. Among Siyakha Nentsha boys, those who received financial education (compared to those who received the health and social education only) were more likely to have reported undertaking an income-generating activity between survey rounds. 
The program had a greater impact than expected. It is encouraging to see strong effects, not only for girls, but also among boys. There are few comprehensive and interactive adolescent interventions such as this one and even fewer that reach both boys and girls together. Programs such as Siyakha Nentsha that include training related to human rights, financial planning, and skills for making better choices in life can provide young people with valuable skills that reduce their risks of acquiring HIV, increase their financial empowerment, and enhance their ability to cope with the stresses of growing up in a challenging environment. The critical period for these young people lies ahead, as they make the transition to adulthood

\section{Reference}

Shisana O, Rehle T, Simbayi LC, Zuma K, Jooste S, Pillay-van-Wyk V, Mbelle N, Van Zyl J, Parker W, Zungu NP, Pezi S \& the SABSSM III Implementation Team (2009). South African national HIV prevalence, incidence, behaviour and communication survey 2008: A turning tide among teenagers? Cape Town: HSRC Press.

\section{Partner Institutions}

Isihlangu Health and Development Agency

HEARD at the University of KwaZulu-Natal, Accudata

Funders

DFID via Healthy Transitions

DFID via the ABBA Research Programme Consortium

Economic and Social Research Council

Hewlett Foundation

\section{Population Council}

The Population Council changes the way the world thinks about critical health and development issues. We seek to understand the causes and consequences of gender inequality and the disparities in opportunity that arise during adolescence. We provide the evidence for better on-theground programs and policies that ensure successful and productive transitions to adulthood in developing countries. www.popcouncil.org

C 2011 The Population Council, Inc 